\title{
AN EXPERIMENTAL STUDY EVALUATING THE INFLUENCE OF BISPHOSPHONATES ON DEPRESSION PATTERNS IN SWISS ALBINO MICE AND WISTER RATS
}

\author{
AMITHA N, S. S. TORGAL \\ Department of Pharmacology and Pharmacotherapeutics, J. N. Medical College, Belagavi 590010, Karnataka, India \\ Email: ss.torgal.hm@gmail.com
}

Received: 31 Mar 2017 Revised and Accepted: 30 Jun 2017

\begin{abstract}
Objective: Bisphosphonates are used for treating osteoporosis. Few studies have reported their effect on alterations in comorbid behaviour such as depression. Therefore, present study was performed to investigate the effects of bisphosphonate drugs on depression in adult male Wister rats and Swiss albino mice.

Methods: The study was conducted on adult male Wister rats and Swiss albino mice, 36 of each type, equally divided into six groups. One group was classified as control group and the rest were treated as test groups. Initial photoperiod of $12 \mathrm{~h}$ was provided for acclimatization, prior to the start of the experiment. Drug administration was not performed in control group. Forced swimming test and tail suspension test were performed to investigate the antidepressant activity. Locomotor activity was performed to evaluate the action of drugs on the nervous system. Effects of the test drugs were compared with a standard drug-amitriptyline. Results were statistically evaluated by one-way analysis of variance followed by Bonferroni's multiple comparison test. $P \leq 0.05$ was considered significant.

Results: In forced swimming test, duration of immobility was significantly reduced in the standard and test drugs when compared to control group; however, it was not significant in all the four test groups as compared to that of amitriptyline-administered group $(p>0.05)$. In tail suspension test, significant decrease $(p<0.01)$ in the duration of immobility was observed with administration of drugs when compared to control group. Results of test groups were not found to be significant as compared to amitriptyline-treated group $(p>0.05)$. Mean values of amitriptyline-, alendronate-, risedronate-, ibandronate-and etidronate-treated groups failed to show significant difference $(p>0.05)$ when compared to control group suggesting homogeneity among the groups.
\end{abstract}

Conclusion: Bisphosphonates appeared to have an antidepressant activity. More extensive research is required to substantiate and elucidate the role of bisphosphonates in behavioural disorders such as depression.

Keywords: Bisphosphonates, Depression, Amitriptyline

(C) 2017 The Authors. Published by Innovare Academic Sciences Pvt Ltd. This is an open access article under the CC BY license (http://creativecommons.org/licenses/by/4.0/) DOI: http://dx.doi.org/10.22159/ijpps.2017v9i8.18829

\section{INTRODUCTION}

Depression, a mental disorder, is often associated with receding bone mineral density (BMD). It has been reported that antidepressants, particularly in the aged population, are a cause of low bone strength and fractures $[1,2]$. In addition, the antidepressants that target the serotonin system have been found to be detrimental for bone health and cause osteoporosis [3].

A relationship between depression and osteoporosis has become more evident over the years, as decreased BMD has been observed in depressed women and men. Compared to older women, aged men appear to be more susceptible to the effects of depression on BMD [4]. It has also been observed that depressed men have lower bone mass than non-depressed men [5]. Studies on animals have also suggested that depression may predispose to osteoporosis. Recent long-term studies have also shown an association between menopausal status with higher risk of depression and osteoporosis [6].

The positive effects of bisphosphonates, including improvement in anxiety or depression [7], are an area of research in the recent years. A study conducted by Kastelan et al. revealed that ibandronate treatment lead to significant improvement in mobility and the condition of depression [8]. Alendronate, on the other hand, significantly decreased the duration of immobility and increased the motor activity and thus can be assumed to play a role in reducing the symptoms of depression [9].

The application of bisphosphonates, especially risedronate, ibandronate and etidronate in the treatment of depression along with osteoporosis is limited. In addition, only few studies are available with respect to evaluation of alendronate in the treatment of depression [10]. Therefore, the present study was undertaken to evaluate the effects of bisphosphonates, such as alendronate, risedronate, ibandronate and etidronate on depression in adult male Wister rats and Swiss albino mice

\section{MATERIALS AND METHODS}

Test animals

Adult male Wistar rats weighing $175 \pm 25 \mathrm{~g}$ and adult male Swiss albino mice weighing $25 \pm 5 \mathrm{~g}$, housed under standard laboratory conditions, were obtained from the central animal house of J. N. Medical College, Belagavi. They were acclimatized to a photoperiod of $12 \mathrm{~h}$ for $10 \mathrm{~d}$ prior to the day of experimentation. Animals were provided feed (standard chow pellet) and water ad libitum. On experimental days, they were sustained on water, as the test drugs had poor intestinal absorption, especially in the presence of food [11]. Wistar rats and Swiss albino mice (36 of each type) were used for experimental purpose. The study was approved by Indian Animal Ethics Committee (IAEC) as per the guidelines of Committee for the Purpose of Control and Supervision of Experiments on Animals (CPCSEA).

\section{Chemicals}

Antidepressant amitriptyline was procured from Merind Ltd. (Wockhardt Ltd.). The test antidepressants-alendronate and risedronate were obtained from Cipla Ltd., ibandronate and etidronate were procured from Sun Pharmaceuticals Ltd., and Vardhaman Health Specialities, Bangalore, respectively.

\section{Dosage}

The Wister rats and Swiss albino mice (36 each) were divided into six groups where one group was designated as control group and the 
rest of the as test groups. Drug administration was not done in the control group. Each group comprised of six rats or mice. Antidepressants were administered orally by dissolving in distilled water. Clinical doses for these drugs were converted into rat or mouse-equivalent doses with the help of the table devised by Paget and Barnes (table 1) [12] and effect of each drug on animals was individually evaluated. A 24-h fasting period was observed prior to the start of the experiment.

Table 1: Number of groups, drugs and dosages used in the study

\begin{tabular}{lllll}
\hline Groups & Treatment & Human clinical dose $\mathbf{( m g )}$ & Rat equivalent dose (p. o, mg/kg) & Mouse equivalent dose (p. o, mg/kg) \\
\hline 1 & Control & - & $0.5 \mathrm{ml}$ & $0.5 \mathrm{ml}$ \\
2 & Amitriptyline (Standard) & 300 & 27 & 39 \\
3 & Alendronate & 5 & 0.45 & 0.65 \\
4 & Risedronate & 5 & 0.45 & 0.65 \\
5 & Ibandronate & 2.5 & 0.225 & 0.325 \\
6 & Etidronate & 5 & 0.45 & 0.65 \\
\hline
\end{tabular}

p. o.: per orally

\section{Behavioural studies}

Antidepressant activity was assessed using the forced swimming test (FST) in Wistar rats and tail suspension test (TST) in Swiss albino mice. Amitriptyline was treated as the standard antidepressant drug for comparison. Locomotor activity was performed and simultaneous measurements of locomotion, exploratory behaviour and anxiety were taken. Behavioural studies were carried out in the afternoon $(2: 00 \mathrm{pm}$ to 5:00 pm) under low illumination.

\section{FST}

The rats were more selective for this experiment, as they give less false positives and hence were preferred over the mice for this experiment [13]. The rats were subjected to a two-session test. The first session (pre-test) was conducted for $15 \mathrm{~min}$ prior to the drug administration with no behavioural recording. After $24 \mathrm{~h}$, the test session was performed for $6 \mathrm{~min}$ in which rats were initially administered with the respective drug three times: at $24 \mathrm{~h}, 5 \mathrm{~h}$ and 1 $\mathrm{h}$. The rats were then held in water maintained at $25 \pm 2^{\circ} \mathrm{C}$ in a vertical Plexiglas cylinder (40 $\mathrm{cm}$ deep and $18 \mathrm{~cm}$ diameter). The duration of immobility (in seconds) was video recorded for each of the test drugs $[13,14]$.

\section{TST}

A modified version of the test was performed with an increase in the distance between the base and the snout of the mouse to enhance sensitivity of the test. Stress was induced in the test mice by suspending the animal by its tail with a distance of $58 \mathrm{~cm}$ between the base and the snout of the mice. Immobility time (in seconds) was recorded for 6 min [13].

\section{Locomotor activity}

It helps to rule out any influence of the drugs on locomotor system, which in turn may affect immobility. Pretreated mice were placed in the centre of the apparatus for $5 \mathrm{~min}$. The device electronically counts the number of times the infrared beams are interrupted by movement of the animal, which in turn is the measure of the locomotor activity $[15,16]$.

\section{Statistical analysis}

Data, expressed as mean $\pm S D$, were analysed by using one-way analysis of variance (ANOVA) and Bonferroni's multiple comparison test [17] with the help of GraphPad Prism 4.0 software. $p \leq 0.05$ was considered as statistically significant.

\section{RESULTS}

\section{Behavioural studies}

\section{FST in adult male wistar rats}

Duration of immobility was significantly reduced in the standard and test drugs when compared to control group (fig. 1). Also, all the four test groups were found to be insignificant as compared to that of amitriptyline-administered group ( $p>0.05$; table 2$)$.

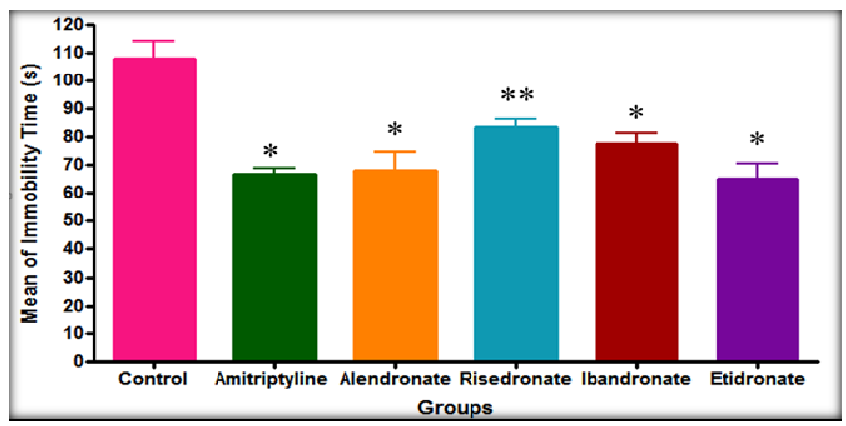

Fig. 1: Effect of various treatments on forced swimming test $\left({ }^{*} p<0.001\right.$ as compared to control; ${ }^{* *} p<0.05$ as compared to control); data are represented as mean $\pm S D$

Table 2: Effect of various drugs in behavioural paradigms

\begin{tabular}{llllll}
\hline & Mean difference in seconds (s) & & & \\
\hline Tests & $\begin{array}{l}\text { Control } \\
\text { (n=6) }\end{array}$ & $\begin{array}{l}\text { Amitriptyline } \\
(\mathbf{n = 6 )}\end{array}$ & $\begin{array}{l}\text { Alendronate } \\
(\mathbf{n}=\mathbf{6})\end{array}$ & $\begin{array}{l}\text { Risedronate } \\
(\mathbf{n}=\mathbf{6})\end{array}$ & $\begin{array}{l}\text { Ibandronate } \\
(\mathbf{n}=\mathbf{6})\end{array}$ \\
\hline FST & $108.2 \pm 14.8$ & $70.17 \pm 7.13$ & $63.17 \pm 24.47$ & $72.83 \pm 31.15$ & $77.83 \pm 8.23$ \\
TST & $129.2 \pm 20.20$ & $71.00 \pm 8.46$ & $75.40 \pm 17.26$ & $77.00 \pm 6.32$ & $87.40 \pm 4.21$ \\
Locomotor activity & $438.2 \pm 166.5$ & $412.8 \pm 73.02$ & $395.8 \pm 49.71$ & $404.6 \pm 124.0$ & $417.0 \pm 55.54$ \\
\hline
\end{tabular}

Data expressed as mean \pm SD; FST: Forced swimming test; TST: Tail suspension test 
TST in male swiss albino mice

The standard, amitriptyline and the test groups showed significant decrease $(p<0.01)$ in the duration of immobility when compared to control group (fig. 2). All the four test groups were found to be insignificant as compared to that of amitriptyline-treated group ( $p>0.05$, table 2$)$.

\section{Locomotor activity}

The mean values of amitriptyline-, alendronate-, risedronate-, ibandronate-and etidronate-treated groups failed to show significant difference $(p>0.05)$ when compared to control group (table 2) suggesting homogeneity among the groups (fig. 3 ).

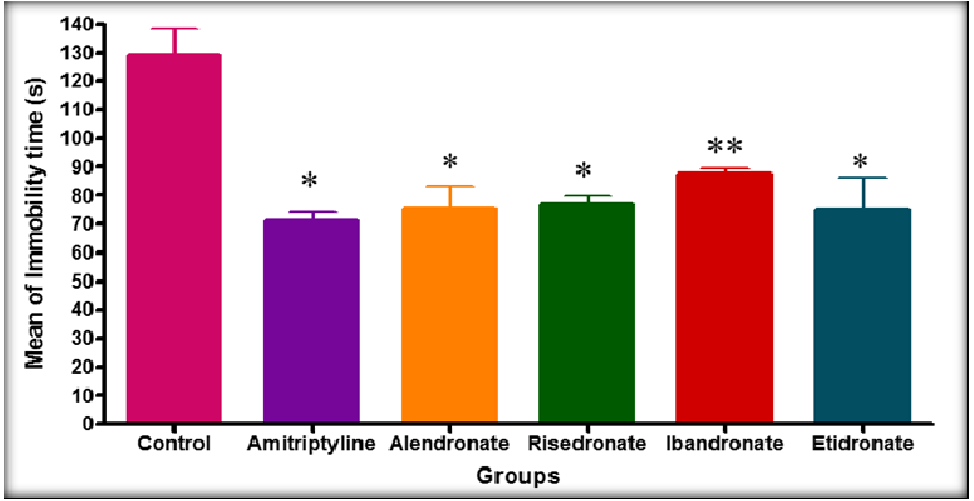

Fig. 2: Effect of various treatments in tail suspension test $\left({ }^{*} p<0.001\right.$ as compared to control; ${ }^{* *} p<0.01$ as compared to control); data are represented as mean $\pm \mathrm{SD}$

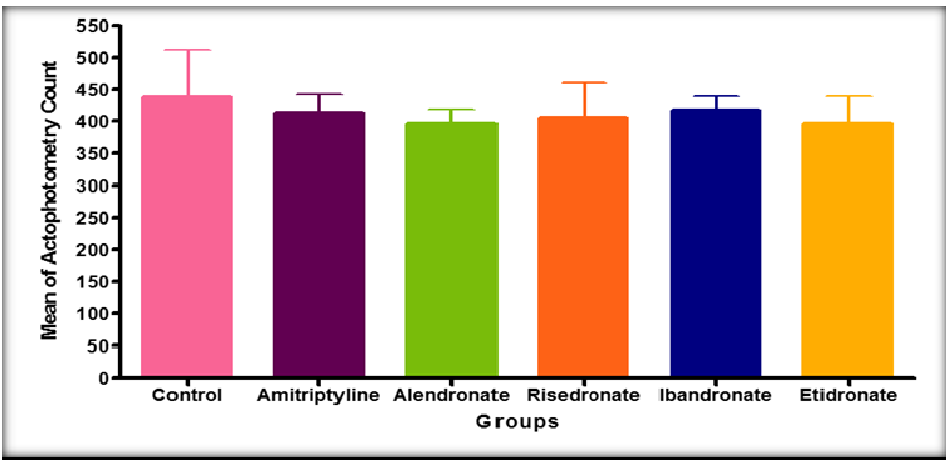

Fig. 3: Effect of various treatments on locomoter activity; data represented as mean \pm SD

\section{DISCUSSION}

Depression, one of the leading mental disorders, is widely associated with other diseases such as osteoporosis. As a result of depression and dysthymia, a decrease in BMD has been observed in men, as well as in adolescent girls and women $[18,19]$.

In the present study, antidepressant activities of alendronate, risedronate, ibandronate and etidronate were evaluated using experimental models of depression. The effects of these drugs on locomotor performance were also evaluated. FST in adult male Wistar rats and TST in adult male Swiss albino mice were performed to evaluate the antidepressant activity of the selected bisphosphonates.

The depression paradigms, FST and TST, were preferred because they were convenient and gave rapid results [16]. The results revealed that the administration of the selected bisphosphonates displayed lesser duration of immobility than the control signifying that these drugs can have antidepressant-like activity.

The effects of drugs on locomotor activity, verified using actophotometer test, displayed no significant difference among the six groups suggesting minimal influence of the drugs on the locomotor system. The actophotometer test is often selected, as it provides measures of locomotion [20]. It also helps to differentiate between the effects of sedative and stimulant drugs.
Bisphosphonates inhibit osteoclasts and have anti-apoptotic effect on osteoblasts. Consequently, they prevent bone weakening. Several studies have reported the decrease in cytokine level as a result of bisphosphonate activity [21-23]. Bisphosphonates, such as risedronate, have been reported to reduce the cytokine level to a significant level and are also involved in inhibiting bone resorption [23]. On the other hand, etidronate has been found to have inhibitory effect on the macrophages for the secretion of cytokine [24]. The anti-inflammatory activity of ibandronate has also been studied and verified by Bianchi et al. [25]. Elevated levels of cytokines are detected in depression and may lead to low BMD. It has been established that anti-inflammatory drugs help in reduction of depression symptoms [26]. Thus, reduction in the level of cytokines by bisphosphonates could be a possible mechanism to reduce depression and increase bone density.

Studies involving osteoporotic patients with rheumatoid arthritis (RA) were conducted within study periods of $1.5 \mathrm{y}$ and $3 \mathrm{y}$ to determine the inhibiting property of the intermittent cyclical etidronate on bone resorption or inflammatory changes. It was found that etidronate inhibited the synthesis of mediators related to inflammation, pain, and angiogenesis [27]. Thus, by reducing the mediators of inflammation, these drugs can be hypothesised to have antidepressant activity.

Depression is one of the common symptoms associated with hyperparathyroidism and hypercalcaemia, which in turn cause bone loss $[28,29]$. As bisphosphonates are used to prevent the bone loss 
in the body, they have also been found to reduce hypercalcaemia and hyperparathyroidism, although at different doses [30]. Although, few reports suggest that bisphosphonates, such as alendronate or risedronate, have adverse effects on primary hyperparathyroidism patients such as increase in the level of parathyroid hormone [31].

Although bisphosphonates are among the first choice of drugs for the treatment of bone disorders such as osteoporosis, they have also been found to cause several adverse effects [32]. Most important long-term side effects of this class of drug are osteonecrosis of the jaw, atrial fibrillation, renal failure, nephrotic syndrome, femoral fractures and severe suppression of bone turnover. Other most commonly reported short-term side effects include severe musculoskeletal pain, hypocalcaemia, oesophageal cancer, electrolyte imbalance and ocular inflammation [33, 34]. Even though several studies have stated these effects, there are the reports arguing against any definite link between the side effects and bisphosphonates. Some of the conditions may be due to long-term accumulation of the drugs in the body or some predisposing condition, such as chronic kidney disease present in the patient administered with bisphosphonates [35]. In cases of drug accumulation, patients are often put on 'drug holiday' in which the bisphosphonate therapy is stopped for a period of time [36]. Trials conducted also indicate that the risk of fractures is low even in women when bisphosphonates were administered for more than $10 \mathrm{y}$ [37].

\section{CONCLUSION}

Bisphosphonates, such as alendronate, risedronate, ibandronate and etidronate have shown significant decrease in the duration of immobility as compared to the standard antidepressant drugamitriptyline. However, further studies including the evaluation of their effect on biochemical profiles and stress levels are required to establish their role as antidepressant drugs.

\section{ACKNOWLEDGEMENT}

None

\section{CONFLICT OF INTERESTS}

The Author(s) declare(s) that they have no conflicts of interest to disclose

\section{AUTHOR CONTRIBUTION}

SST designed the study and prepared the manuscript. AN acquired and analysed the data and prepared the initial draft of the manuscript.

\section{REFERENCES}

1. Landi F, Onder G, Cesari M, Barillaro C, Russo A, Bernabei R, et al. Psychotropic medications and risk for falls among community-dwelling frail older people: an observational study. J Gerontol Ser A 2005;60:622-6.

2. Takkouche B, Montes-Martinez A, Gill SS, Etminan M. Psychotropic medications and the risk of fracture. Drug Saf 2007;30:171-84.

3. Rizzoli R, Cooper C, Reginster JY, Abrahamsen B, Adachi JD, Brandi ML, et al. Antidepressant medications and osteoporosis. Bone 2012;51:606-13.

4. Rauma PH, Pasco JA, Berk M, Stuart AL, Koivumaa-Honkanen H, Honkanen RJ, et al. The association between major depressive disorder, use of antidepressants and bone mineral density (BMD) in men. J Musculoskeletal Neuronal Interact 2015;15: 177-85.

5. Cizza G, Primma S, Csako G. Depression as a risk factor for osteoporosis. Trends Endocrinol Metab 2009;20:367-73.

6. Frey BN, Lord C, Soares CN. Depression during menopausal transition: a review of treatment strategies and pathophysiological correlates. Menopause Int 2008;14:123-8.

7. Aithal S, Hooli TV, Patil R, Varun HV, Swetha ES. Evaluation of antidepressant activity of topiramate in mice. Asian J Pharm Clin Res 2014;7:174-6.

8. Kastelan D, Vlak P, Lozo P, Gradiser M. Health-related quality of life among patients with postmenopausal osteoporosis treated with weekly and monthly bisphosphonates. Endocr Res 2010;35:165-73.
9. Citraro R, Gallelli L, Leo A, De Fazio P, Gallelli P, Russo E, et al. Effects of chronic sodium alendronate on depression and anxiety in a menopausal experimental model. Pharmacol Biochem Behav 2015;129:65-71.

10. Citraro R, Gallelli L, Leo A, De Fazio P, Gallelli P, Russo E, et al. Effects of chronic sodium alendronate on depression and anxiety in a menopausal experimental model. Pharmacol Biochem Behav 2015;129:65-71.

11. Sweetman SCM. The complete drug reference. $36^{\text {th }}$ ed. London: Pharmaceutical Press; 2009. p. 1088-91.

12. Ghosh MN. Toxicity studies. Fundamentals of experimental pharmacology. $4^{\text {the }}$ d: Kolkata: Hilton and company; 2005. p. 176-83.

13. Castagné V, Moser P, Roux S, Porsolt RD. Rodent models of depression: forced swim and tail suspension behavioral despair tests in rats and mice. Chapter 8. Curr Protoc Neurosci 2011.

14. Castagné V, Moser P, Porsolt RD. Behavioral assessment of antidepressant activity in rodents. In: Buccafusco JJ. editor. Methods of Behavior Analysis in Neuroscience. 2nd edition. Boca Raton (FL): Chapter 6. CRC Press; 2009.

15. Yadav G, Garg VK, Thakur R, Khare P. Locomotor activity of methanolic extract of Saracaindica Bark. Adv Biol Res 2013;7:1-3.

16. Vogel HG. Drug discovery and evaluation: Pharmacological assays. $3^{\text {rd }}$ Ed. New York: Springer; 2008.

17. DeMuth JE. Basic statistics and pharmaceutical statistical applications. $2^{\text {nd }}$ ed. Boca Raton (FL): Chapman and Hall/CRC Press: Chapter 11. Multiple comparison tests; 2006. p. 229-66.

18. Konstantynowicz J, Kadziela-Olech H, Kaczmarski M, Zebaze RM, Iuliano-Burns S, Piotrowska-Jastrzebska J, et al. Depression in anorexia nervosa: a risk factor for osteoporosis. J Clin Endocrinol Metab 2005;90:5382-5.

19. Mussolino ME, Jonas BS, Looker AC. Depression and bone mineral density in young adults: results from NHANES III. Psychosom Med 2004;66:533-7.

20. Umarani V, Sudhakar M, Ramesh A, Lakshmi BVS, Sandhyarani D. Protective effect of hydroalcoholic extract of Pueraria tuberosa against arsenic induced neurotoxicity in rats. Int J Res Pharmacol Chem 2016;6:350-62.

21. Tamai R, Sugiyama A, Kiyoura Y. Alendronate regulates cytokine production induced by lipid A through nuclear factor $-\kappa \mathrm{B}$ and Smad3 activation in human gingival fibroblasts. J Periodontal Res 2011;46:13-20.

22. Vogelzangs $\mathrm{N}$, De Jonge $\mathrm{P}$, Smit JH, Bahn S, Penninx BW. Cytokine production capacity in depression and anxiety. Transl Psychiatry 2016;6:e825.

23. D'Amelio P, Grimaldi A, Di Bella S, Tamone C, Brianza SZ, Ravazzoli MG, et al. Risedronate reduces osteoclast precursors and cytokine production in postmenopausal osteoporotic women. J Bone Miner Res 2008;23:373-9.

24. Pennanen N, Lapinjoki S, Urtti A, Mönkkönen J. Effect of liposomal and free bisphosphonates on the IL-1 $\beta$, IL- 6 and TNF $\alpha$ secretion from RAW 264 cells in vitro. Pharm Res 1995;12:916-22.

25. Bianchi M, Franchi S, Ferrario P, Sotgiu ML, Sacerdote P. Effects of the bisphosphonate ibandronate on hyperalgesia, substance $\mathrm{P}$, and cytokine levels in a rat model of persistent inflammatory pain. Eur J Pain 2008;12:284-92.

26. Raison CL, Rutherford RE, Woolwine BJ, Shuo C, Schettler P, Drake DF, et al. A randomized controlled trial of the tumor necrosis factor antagonist infliximab for treatment-resistant depression: the role of baseline inflammatory biomarkers. JAMA Psychiatry 2013;70:31-41.

27. Nagashima M, Takahashi H, Shimane K, Nagase $Y$, Wauke K. Osteogenesis and osteoclast inhibition in rheumatoid arthritis patients treated with bisphosphonates alone or in combination with pitavastatin over an 18-month follow-up after more than $4 \mathrm{y}$ of treatment with bisphosphonates. Arthritis Res Ther 2012;14:1-8.

28. David AA, Schoeber J, Houston RE, Mohl VE, Wildman KM. Hyperparathyroidism. Am Fam Physician 1998;57:1795-802.

29. Pamulaparthi A, Prathap VR, Banala M, Nanna RS. Experimental evaluation of antidepressant and antianxiety activities of 
aqueous leaf extracts of Senna alata (1.) Roxb. using in vitro animal models. Int Curr Pharm Res 2016;8:60-3.

30. Rodan DA. Bisphosphonates and primary hyperparathyroidism. J Bone Miner Res 2002;17 Suppl 2:N150-3.

31. Knight MJ, Hyatt PJ. The effect of bisphosphonates on calcium and parathyroid hormone levels in patients with primary hyperparathyroidism over 2 y. Endocrine Abstracts; 2006. p. 12 P2.

32. Gill R, Balaji O, Kumari MK, Amberkar MB, Udupa KS. Zoledronic acid: a mischievous suspect for liver injury. Asian J Pharm Clin Res 2016;9:3-6.

33. Kennel KA, Drake MT. Adverse Effects of bisphosphonates: Implications for osteoporosis management. Mayo Clin Proc 2009;84:632-8.

34. Tanvetyanon T, Stiff PJ. Management of the adverse effects associated with intravenous bisphosphonates. Ann Oncol 2006;17:897-907.
35. Papapetrou PD. Bisphosphonate-associated adverse events. Hormones 2009,8:96-110.

36. Diab DL, Watts NB. Bisphosphonate drug holiday: who, when and how long. Ther Adv Musculoskelet Dis 2013; 5:107-11.

37. Black DM, Kelly MP, Genant HK, Palermo L, Eastell R, BucciRechtweg C, et al. Bisphosphonates and fractures of the subtrochanteric or diaphyseal femur. $\mathrm{N}$ Engl J Med 2010;362:1761-71.

\section{How to cite this article}

- $\quad$ SS Torgal, Amitha N. An experimental study evaluating the influence of bisphosphonates on depression patterns in swiss albino mice and wister rats. Int J Pharm Pharm Sci 2017;9(8):187-191. 